\title{
Study on Non-Darcian Flow in Interlayer Shear Weakness Zones in the Basalt by High-Pressure Packer Tests
}

\author{
Qi Shen ${ }^{D},{ }^{1}$ Zhifang Zhou ${ }^{\mathbb{D}},{ }^{1}$ Meng Chen, ${ }^{2}$ Zhe Wang, ${ }^{1}$ and Yabing Li $^{1}$ \\ ${ }^{1}$ School of Earth Science and Engineering, Hohai University, Nanjing 211100, China \\ ${ }^{2}$ Nanjing Institute of Environmental Sciences, Ministry of Ecology and Environment, Nanjing 210042, China \\ Correspondence should be addressed to Zhifang Zhou; zhouzf@hhu.edu.cn
}

Received 15 April 2021; Accepted 8 June 2021; Published 28 October 2021

Academic Editor: Yong Liu

Copyright (C) 2021 Qi Shen et al. This is an open access article distributed under the Creative Commons Attribution License, which permits unrestricted use, distribution, and reproduction in any medium, provided the original work is properly cited.

\begin{abstract}
The interlayer shear weakness zone (ISWZ) is a special structural plane with different widths and spacing in stratified rock masses, it has higher permeability compared with surrounding rocks which is a risk factor for the safety of the hydropower station project. The high-pressure packer test (HPPT) by step injection is always applied to characterize the permeability of ISWZ. However, the non-Darcian flow is easy to appear under high pressure, which makes the Darcy law model no longer applicable. In this study, two non-Darcian flow analytical methods for confined aquifer were proposed to investigate the non-Darcian flow permeability parameters. The equivalent permeability coefficients of different non-Darcian models were derived as well. The in situ tests were conducted on the ISWZs at the Baihetan hydropower station to verify the proposed methods. The results indicate that the flow is non-Darcian flow in the test section from integrity to destruction during the whole HPPT process. Izbash's law has a better fit than Forchheimer's law in this complicated test situation. The equivalent permeability coefficients after destruction are one or two orders of magnitude larger than those before. Meanwhile, it is necessary to pay attention to the increased difference of two expressions of the equivalent permeability coefficients under higher gradient $(i)$ or velocity $(v)$. In general, these methods can be used to evaluate the characteristic of ISWZ to analyze the impact on engineering stability.
\end{abstract}

\section{Introduction}

The interlayer shear weakness zone (ISWZ) is a special structural plane widely distributed in the rock mass, especially in some large hydraulic projects in China. With the construction of high-head hydraulic power stations, the influence of the ISWZ is important to the stability of the project. The structure of ISWZs is loose, with fractured rocks and high clay content which provides the main channels for groundwater flow. After reservoir impoundment, the groundwater flow may deviate from Darcy's law as the velocity or hydraulic gradient increases due to high water head difference, it is completely different from the existing Darcian flow model. However, the effect of non-Darcian flow in the ISWZ is yet a lack of research.

The ISWZ is caused by the localization of shear within relatively narrow zones in fault rocks, these fault rocks change due to the operation of physicochemical mechanisms related either directly or indirectly to deformation and often controlled by fluids. A conceptual model with a superposition of shear behaviours of interlayer soil and rock interface to predict the shear strength of ISWZ has been developed by $\mathrm{Xu}$ et al. [1], he investigated the shear behaviour of a weak interlayered soil in the host rock and the soil-host rock interface by direct shear testing in the laboratory under different degrees of saturation [2], and used the equivalent continuum approach to evaluate the stability of the future Baihetan underground powerhouse that is affected by ISWZs [3]. Chen et al. [4] found that ISWZs can be regarded as being filled by the low-permeability fillings (mud and debris) and the high-permeability fillings (gravel and fractured surrounding rock). Considering the scaling variation in ISWZs, the hydraulic conductivity values of the interlayer staggered zones tend to converge as the scale increases, and the recommended values of hydraulic conductivity for ISWZs in the Baihetan hydropower project was proposed [5].

The high-pressure packer test is a step hydraulic injection test as a method for the determination of the 
hydro-mechanical properties of the fractured rock mass. It has been widely used in the fields of hydrogeology. For example, Cornet et al. [6] investigated the pressure domain within which hydromechanical coupling significantly influences the hydrologic behavior of a rock mass; Cappa et al. [7] analyzed the in-situ fracture mechanical deformation and fluid flow interactions; Derode et al. [8] evaluated the role of fluids and stress transfer in the triggering of seismicity and deformations in fractured media; Huang et al. [9] showed two phases in water injection tests with differential injection pressure (stable change phase and increase phase) which is caused by hydraulic fracturing. The injection pressure of the packer test is usually controlled at a medium value to avoid hydraulic fracturing, few cases are used to estimate the hydraulic parameter subjected to high water pressure by increasing pressure to fracture failure.

Darcy's law-based equations are widely employed to determine the hydraulic conductivity $(K)$ or the transmissivity $(T)$ values [10-12]. More and more field tests, however, show evidence of non-Darcian flow in the test results including packer test [13] and slug test [14], the flow regime during these tests in the fractured rock are turbulence flow which can lead to underestimation of $T$ by as much as an order of magnitude [15]. The most obvious feature of the HPPT is the high injection pressure, which suggested that the flow in test sections should be possible to generate non-Darcian flow. Some studies began to focus on the non-Darcian flow that occurs in the packer test [16]. Yamada et al. [17] derived an equation adopting Izbash's equation which can be used for any type of flow condition in the packer test. Chen et al. [18] performed HPPTs with the maximum injection pressure up to $7 \mathrm{MPa}$ for understanding the high-pressure groundwater flow behaviours in the surrounding rocks and employed two non-Darcian law-based analytical models to estimate the hydraulic parameter. Recently, they proposed an integrated method combining packer test data interpretation, statistical correlation and inverse modelling to determine the non-Darcian flow properties of the karst aquifer system [19].

Most HPPTs are used to obtain hydraulic parameters in fractured rocks, where few tests are performed to assess parameters for the structural plane in fractured rocks such as the ISWZ. In particular, there are few the study of nonlinear flow. The primary motivation of this paper is to evaluate the non-Darcian flow parameters of the ISWZ under high pressure caused by the HPPT. Firstly, two novel nonlinear analytical models are proposed to describe non-Darcian flow for HPPT, and the non-Darcian flow parameters are obtained by curve fitting to simplify the calculation. Then, two models were applied to interpret in-situ test data in Baihetan Hydropower Station, China. Finally, the variation of equivalent permeability coefficient during the test was obtained. It can provide a reference for further seepage analysis.

\section{Methods}

A schematic diagram of the HPPT system is shown in Figure 1. Hvorslev et al. [20] provided different formulas to

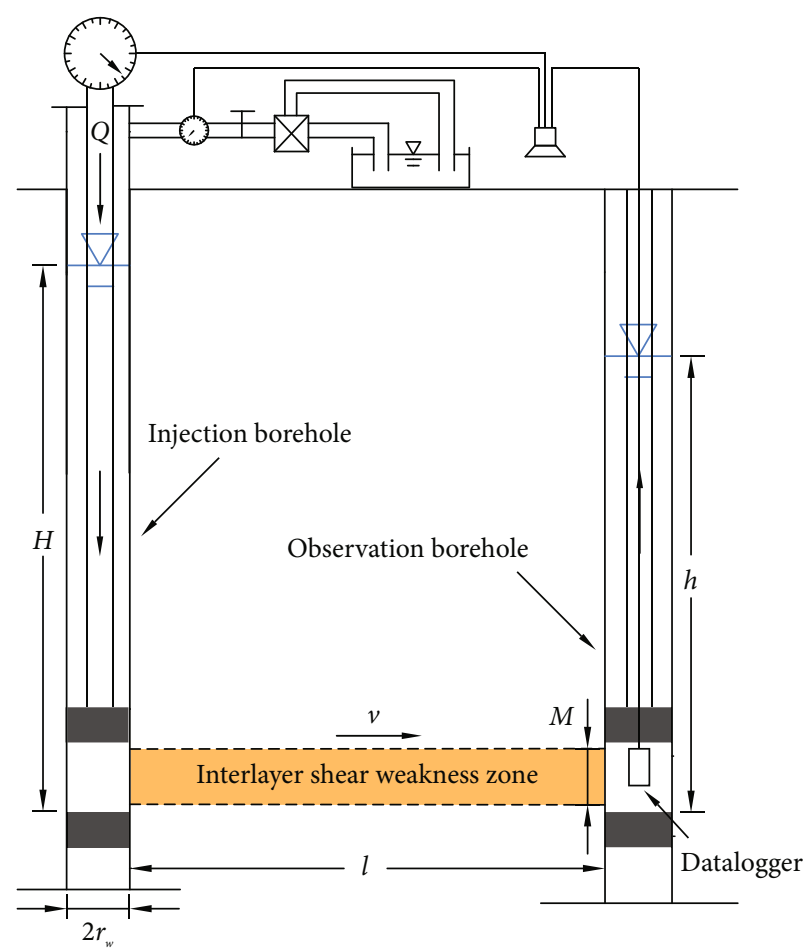

FiguRE 1: Schematic representation of high-pressure packer test.

calculate hydraulic conductivity by using different types of piezometers. Due to the ISWZ has strong anisotropy, the permeability along the strata direction is strong while perpendicular to the strata direction is weak, it is similar to the case that well points through permeable layer between impervious strata. Therefore, the following assumptions can be given that (1) The boundary is infinite. (2) The flow lines are horizontal and the coefficient of horizontal permeability $k$ is governing. (3) The specific discharge $q$ remains unchanged in the axial direction of the borehole.

The radial steady flow governing equation in a complete well with confined water can be simplified as

$$
\frac{d}{d r}\left(r \frac{d H}{d r}\right)=0
$$

where $H$ is the head of the water table, $r$ is the radial coordinate from the centre of the radial flow to an arbitrary boundary. Based on the above assumptions, the specific discharge $q$ can be written as

$$
\begin{aligned}
& q=2 \pi r v \\
& q=\frac{Q}{M}
\end{aligned}
$$

where $v$ is the fluid velocity, $Q$ is a constant volumetric flow rate when the test reaches a stable state, and $M$ is the thickness of ISWZ.

Laminar flow in a porous or fractured medium can be described by Darcy's law. When the energy losses increased by kinematic forces and inertia effects, the turbulent flow 
occurs, the flow will deviate from Darcy's law which is called non-Darcian flow. There are two generally accepted law to describe: Forchheimer's law and Izbash's law.

2.1. Forchheimer's Law. Forchheimer extended Darcy's law with a quadratic term to represent the deviate degree caused by the turbulent flow

$$
i=a v+b v^{2}
$$

where $i$ is the hydraulic gradient, $v$ is the fluid velocity, $a$ and $b$ are the coefficients describing viscous and inertial energy losses, respectively. They can be further written as

$$
\begin{aligned}
& a=\frac{\mu}{\rho g k}=\frac{1}{K} \\
& b=\left|\frac{\beta}{g}\right|
\end{aligned}
$$

where $\mu$ is the fluid dynamic viscosity, $\rho$ is the fluid density, $g$ is the gravitational acceleration, $k$ is the permeability, $\beta$ is the nonlinear flow coefficient, $K$ is the permeability coefficient for laminar flow.

In porous media, the coefficient $a$ in the Forchheimer equation is a linear term that depends on the properties of both the porous medium and the fluid. It represents energy losses due to viscous forces (viscous friction) at the fluidsolid interface. On the other hand, coefficient $b$ is a nonlinear term only depends on the properties of the porous medium which is related to inertial forces [21].

Combing Eq.(2) and Eq.(3), the hydraulic properties ( $k$ and $\beta$ ) in Forchheimer's law can be obtained as

$$
-\frac{d H}{d r}=a \frac{Q}{2 \pi r M}+b\left(\frac{Q}{2 \pi r M}\right)^{2}
$$

The integral equation of Eq.(5) is

$$
-\int_{h_{w}}^{h_{1}} d H=\int_{r_{w}}^{r_{1}}\left[a \frac{Q}{2 \pi r M}+b\left(\frac{Q}{2 \pi r M}\right)^{2}\right] d r
$$

For the packer test with observation borehole, $h_{w}$ is the assumed head of the injection well with the radius $r_{w}$ which can convert by the injection pressure $h_{w}\left(h_{w}=P / \rho g\right)$; and $h_{1}$ is the head of the observation well at $r_{1}$, yields

$$
h_{w}-h_{1}=a \frac{Q}{2 \pi M} \ln \frac{r_{1}}{r_{w}}+b\left(\frac{Q}{2 \pi M}\right)^{2}\left(\frac{1}{r_{w}}-\frac{1}{r_{1}}\right)
$$

When performing the in-situ HPPTs, the injection pressure $(P)$ and volumetric flow rate $(Q)$ in the injection borehole can be obtained, and the head difference can be expressed with $\Delta H=h_{w}-h_{1}$. By corresponding to the Eq.(7), the following Forchheimer equation can be used to fit the $\triangle H-Q$ curves

$$
\Delta H=A Q+B Q^{2}
$$

where

$$
\begin{aligned}
& A=a \frac{1}{2 \pi M} \ln \frac{r_{1}}{r_{w}} \\
& B=b\left(\frac{1}{2 \pi M}\right)^{2}\left(\frac{1}{r_{w}}-\frac{1}{r_{1}}\right)
\end{aligned}
$$

2.2. Izbash's Law. The Izbash's law is an empirical equation which is also called the power-law

$$
v=K_{c} i^{1 / n}
$$

in which $n$ and $K_{c}$ are empirical constants. $K_{c}$ is the nonlinear flow hydraulic permeability, $n$ is the nonlinear flow exponent representing the degree of deviation from linearity.

Integral Eq.(1) becomes

$$
-\frac{d H}{d r}=\frac{C}{r}
$$

Combining Eq.(2) and Eq.(11), we now have

$$
q=2 \pi r K_{c} i^{1 / n}
$$

When Eq.(13) is given to Eq.(12), the constant $C$ is

$$
C=\left(\frac{q}{2 \pi K_{c}}\right)^{n} r^{-n+1}=\left(\frac{Q}{2 \pi M K_{c}}\right)^{n} r^{-n+1}
$$

Hence, Eq.(12) can be written as

$$
d H=\left(\frac{Q}{2 \pi M K_{c}}\right)^{n} r^{-n} d r
$$

The integral form can be expressed as

$$
-\int_{h_{w}}^{h_{1}} d H=\int_{r_{w}}^{r_{1}}\left[\left(\frac{Q}{2 \pi M K_{c}}\right)^{n} r^{-n}\right] d r
$$

When $n=1$, the integral equation of Eq.(15) becomes identical with the Hvorslev equation

$$
h_{w}-h_{1}=\frac{Q}{2 \pi M K_{c}} \ln \left(\frac{r_{1}}{r_{w}}\right)
$$

where $K_{c}$ is equal to the permeability $k$ in this linear condition. When $n \neq 1$, Eq.(16) can be written as

$$
h_{w}-h_{1}=\left(\frac{Q}{2 \pi M K_{c}}\right)^{n} \frac{r_{1}^{-n+1}-r_{w}^{-n+1}}{1-n}
$$

where $h_{w}$ is the assumed head of the injection well with the radius $r_{w}$ which can convert by the injection pressure $h_{w}$ $\left(h_{w}=P / \rho g\right)$; and $h$ is the water head of the observation well at $r$. 
Therefore, the following Izbash equation can be used to fit the $\Delta H-Q$ curves

$$
\Delta H=C_{1} Q^{n}
$$

where

$$
C_{1}=\left(\frac{1}{2 \pi M K_{c}}\right)^{n} \frac{r_{1}^{-n+1}-r_{w}{ }^{-n+1}}{1-n}
$$

2.3. Equivalent Permeability Coefficient. It is well known that the $i-v$ curve directly shows the relationship of the gradient and velocity, the slope of the curve is related to the permeability coefficient. In the case of non-Darcian flow, the value of the permeability coefficient varies from time to time due to the slope of the curve is different at different points. We introduced the equivalent permeability coefficient to quantify the variation.

As the $i-v$ curve shown in Figure 2, choose any point on the curve and connect to the origin point, this line represents the linear relationship between hydraulic head gradient and flow velocity in this point which the value of slop is the reciprocal of equivalent permeability coefficient for linear flow, it is the secant of this point which is called the secant method. On the other hand, the slope of the $i-v$ curve is the reciprocal of the permeability coefficient of the point from the mathematical point of view, the line is the tangent of this point which is called the tangent method. These two values are equal in Darcian flow due to the $i-v$ curve is a straight line, however, these two values will be different when the curve is no longer a straight line. Therefore, the equivalent permeability coefficient can be calculated by these two methods and each method has two expressions according to different non-Darcian models. The summary of these equations shown in Table 1 as follows, where $K_{\text {esf }}$ and $K_{\text {esi }}$ are the equivalent permeability coefficients obtained by the secant method for the Forchheimer equation and the Izbash equation, respectively. In the same way, $K_{e t f}$ and $K_{e t i}$ are the equivalent permeability coefficients for the two nonlinear flow equations obtained by the tangent method.

Many studies use the secant method to describe nonlinearities in the relationship between hydraulic head gradient and flow velocity for further calculation, they combine the Darcian and the non-Darcian flow model to derive the permeability coefficient for non-Darcian flow [22-25]. The permeability coefficient obtained by the tangent method has a clear physical meaning. When the velocity and gradient are low enough, there is little difference between these two values, but the difference is obviously with the increase of velocity and gradient, which shown in Figure 2.

\section{High-Pressure Packer Test}

3.1. Site Description. The Baihetan hydropower station is located downstream of the Jinsha River, China (Figure 3(a)). It is the world's second-largest hydropower project which has a double-curvature arch dam with a maximum height is $289 \mathrm{~m}$ and two large-scale underground powerhouses in the left bank and the right bank, respec-

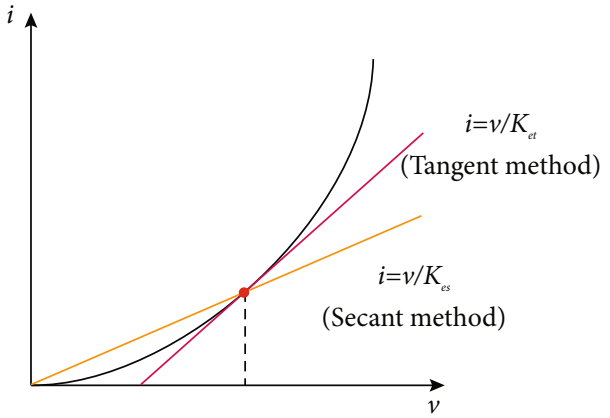

Figure 2: Schematic diagram of the obtained equivalent permeability coefficients by two methods.

TABle 1: Two methods for obtaining the equivalent permeability coefficients by two non-Darcian flow models.

\begin{tabular}{lll}
\hline Type & Secant method & Tangent method \\
\hline Forchheimer's law & $K_{e s f}=1 / a+b v$ & $K_{e t f}=1 / a+2 b v$ \\
Izbash's law & $K_{e s i}=K_{c}{ }^{n} / v^{n-1}$ & $K_{e t i}=K_{c}{ }^{n} / n v^{n-1}$ \\
\hline
\end{tabular}

tively. The Jinsha River flows from south to north in the dam area with a water level of $590 \mathrm{~m}$, the normal reservoir water level of the reservoir is $825 \mathrm{~m}$. The head difference between the upstream and downstream will achieve $235 \mathrm{~m}$ after impoundment.

Basalts of the Upper Permian Emeishan Formation are mainly exposed in the dam area, the Tuff interlayers are developed between each basalt layer except for the top of the first rock layer, and 10 rock layers all have different degrees of structural dislocation, and their spatial distribution is consistent with the occurrence of the rock layers (Figure 3(c)). Interlayer shear weakness zones (e.g., $\mathrm{C}_{2}, \mathrm{C}_{3}$, $\mathrm{C}_{4}$ ) are formed under structural action in these interlayers with a thickness of $5-40 \mathrm{~cm}$. The ISWZ $\mathrm{C}_{2}$ and $\mathrm{C}_{4}$ pass through the whole underground powerhouse in the left bank and right bank, respectively, which has a potential threat to the stability of the underground powerhouse.

Zhou et al. [5] investigated the filling type of the ISWZ in the dam area, it can be divided into four types: intercalated mud, rock debris with intercalated mud, particles and rock. One outcrop of ISWZ is shown in Figure 4 where the distribution location of the fillings can be observed. Different fillings have different permeability characteristics, the mud and debris have a low permeability while the particles and rock have a high permeability. The permeability values of the same ISWZ are different in different positions as well due to the inhomogeneity of the distribution of filling in it, the horizontal permeability of ISWZ generally is much larger than vertical. But the whole ISWZ has a stronger permeability than the Basalts, which constitutes the main structural plane controlling the flow and affects the dam area hydrogeological conditions.

3.2. HPPT Procedure. As is shown in Figures 3(b) and 3(c), two test sites are chosen in left and right banks, one test site is in the target zone $\mathrm{C}_{2}$ of the left bank, numbered as CZK51, 

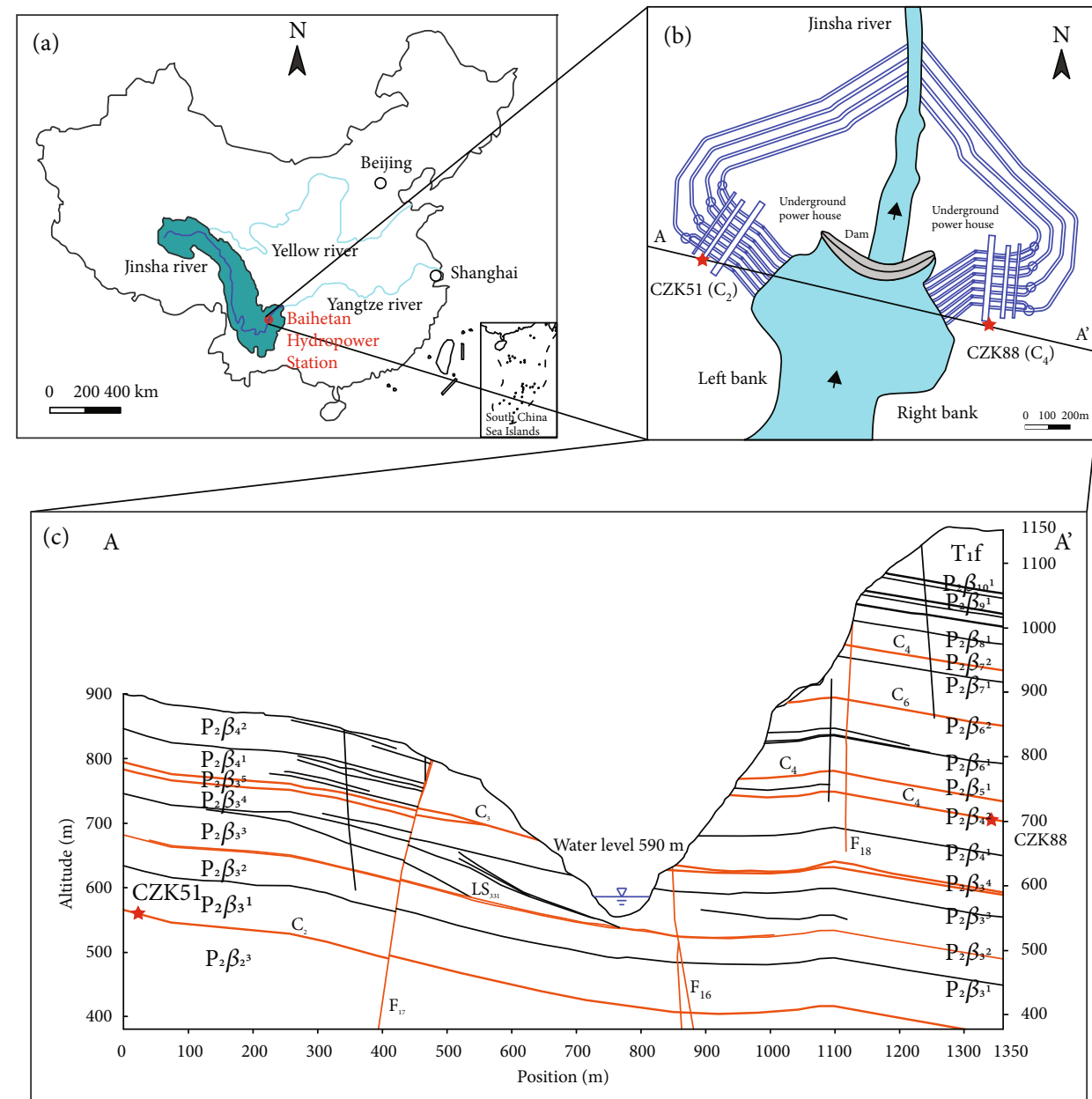

FIgURE 3: The location of the Baihetan hydropower station. (a) Geographical location map of Baihetan hydropower station in China; (b) The layout of hydropower station and the distribution of the test sites; (c) The spatial distribution of main hydrogeological structures and the vertical position of test sites.

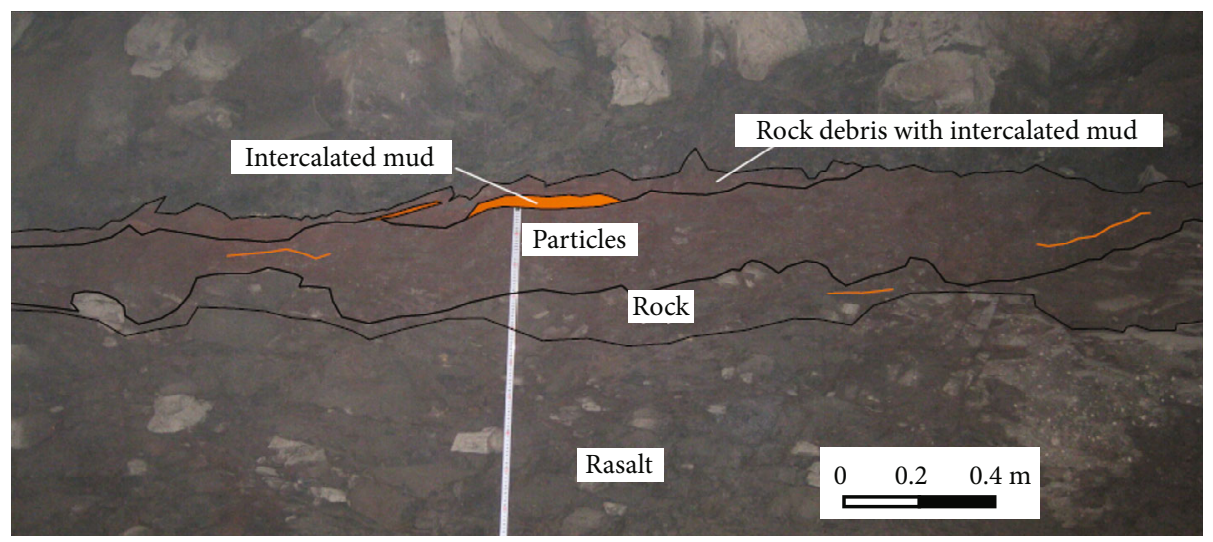

FIgURE 4: Composition of fillings in the interlayer shear weakness zone.

the other test site is in the target zone $\mathrm{C}_{4}$ of the right bank, numbered as CZK88.

3.2.1. Borehole CZK51. The CZK51 is on the east side of the main transformer hole of the left bank, five test boreholes were set up by using water drilling technology with the elevation of the orifice is $570 \mathrm{~m}$. The distribution of these five boreholes is shown in Figure 5. There is less mud content in the staggered belt, debris and gravel are more closely developed, and clay content is lower. Two hydraulic 


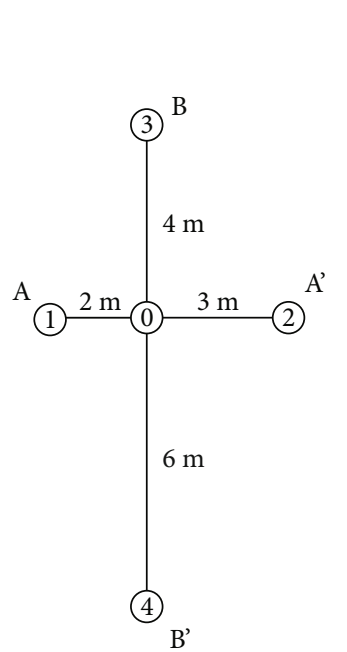

(a)

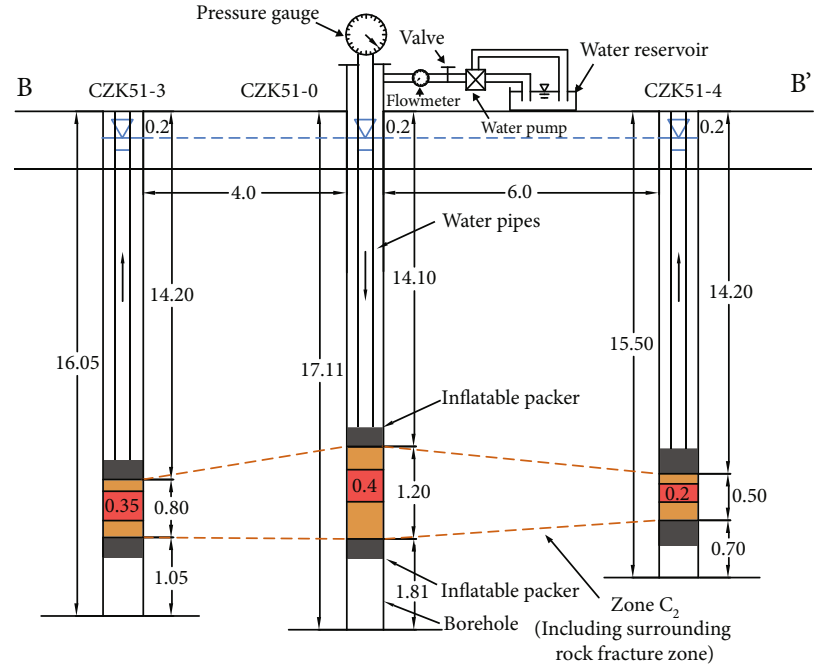

(b)

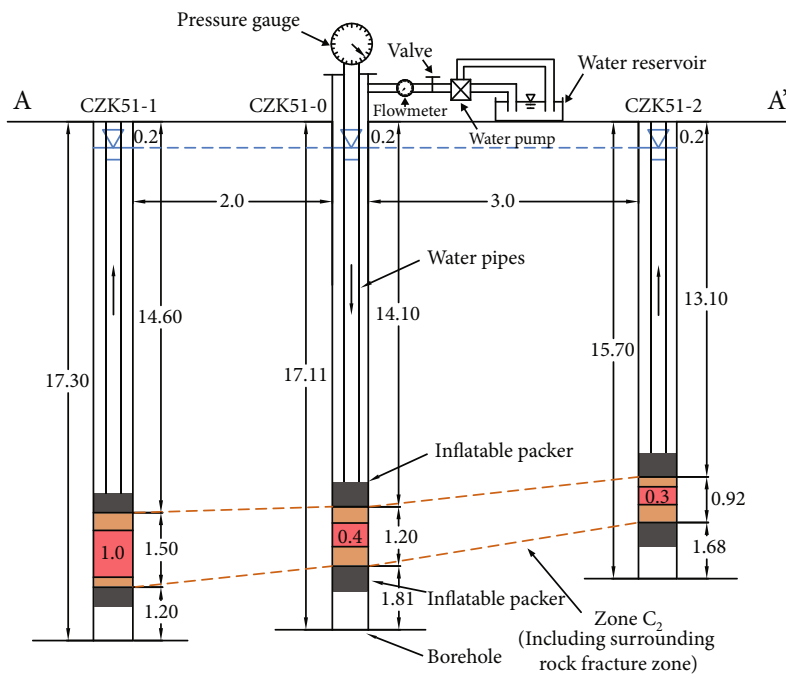

(c)

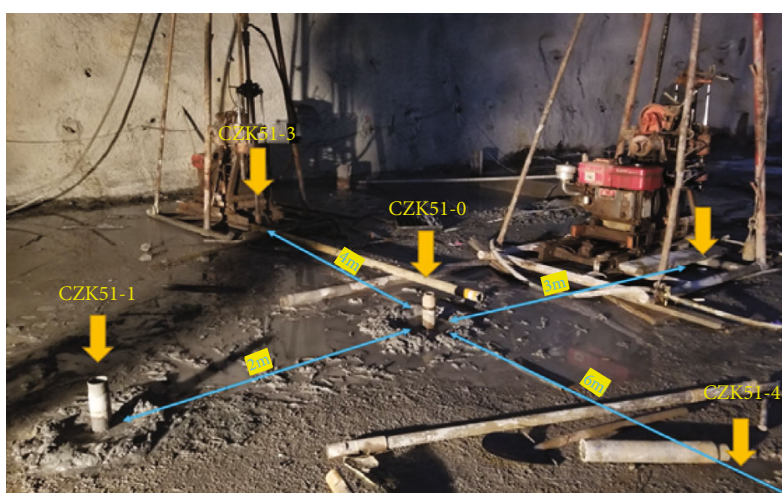

(d)

FIgure 5: The distribution and sectional view of the testing site of borehole CZK51: (a) the spatial distribution of each borehole; (b) the profile of the boreholes in the B-B' section; (c) the profile of the boreholes in the A-A' section; (d) testing field of borehole CZK51 (all dimensions are in units of $\mathrm{m}$ ).

inflatable packers are installed in each borehole to isolate the ISWZ for an accurate injection pressure to the target test section. The flow rate $(Q)$ and water injection pressure $(P)$ of the injection well are measured by the grouting data acquisition and processing system (TIANJIN SAIZHI, FEC-GJ3000) at each pressure stage, and the head of water table of observation wells is recorded during the whole process by the TD-Diver groundwater datalogger (DI1271) which purchased from Schlumberger Co.

As is shown in Figure 6, the whole process can be divided into three stages. The first stage is the undamaged stage at the early stage of the test, the flow rate in the borehole had a light change under the injection pressure $0.3 \mathrm{MPa}$, indicates the test section is complete and water from the injection borehole is slowly passing around. Then the flow rate increased slowly at the middle stage of pressure $0.5 \mathrm{MPa}$, with the head of water table of the observation borehole increased.
The next stage is the transition stage when the injection pressure is up to $0.7 \mathrm{MPa}$, the flow rate and the head of water table of the observation borehole in this stage continuous increased comparing to the last pressure stage. Meanwhile, the water from the observation borehole was limpidity and the test section were remaining intact.

As the injection pressure further increased to $1.0 \mathrm{MPa}$, the flow rate increased rapidly and feculent water founded flowing out from the objection boreholes. It is the damage stage in which significant penetration damage occurred in the test section. Then maintain the injection pressure 1.0 MPa until the flow rate stable, the water from the observation boreholes became clean. At the end of the test, the injection pressure increased to $1.5 \mathrm{MPa}$ for observing whether the secondary damage occurs. Moreover, the reddish-brown water was observed transitory from the CZK51-0 and CZK51-1, indicates the damage was almost 


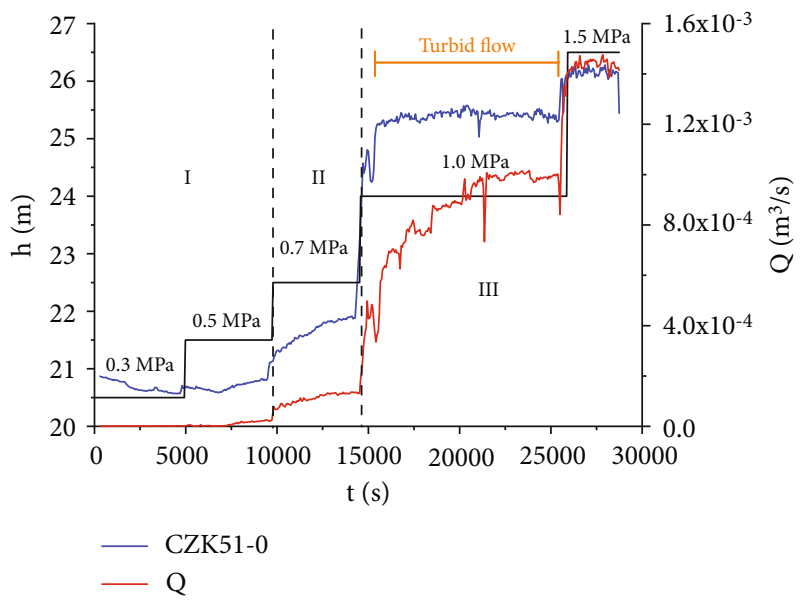

Figure 6: Flow rate and head of water table of observation borehole CZK51-0. It can be divided into three stages according to flow variations and observed turbidity: (I) undamaged stage, (II) transition stage and (III) damaged stage.

complete during the pressure stage 1.0 MPa and no turbid liquid found in the pressure stage $1.5 \mathrm{MPa}$.

3.2.2. Borehole CZK88. The test site CZK88 is in the intersection of the two drainage galleries of the right bank, five test boreholes were set up by using water drilling technology with the elevation of the orifice is $705 \mathrm{~m}$. The distribution of these boreholes shown in Figure 7. It is mainly composed of breccia, cuttings and mud, in which the breccia and debris distributed in the central part. The test equipment and measure devices are the same as the previous test CZK51.

As is shown in Figure 8, the flow rate in the borehole is relatively low when the injection pressure during $0.3 \mathrm{MPa}$ to $1.5 \mathrm{MPa}$, which indicates that the target section has poor permeability. It is the undamaged stage in which the pressed water diffuses slowly. The flow rate and the head of water table of the observation borehole slightly increased with fluctuations when the pressure increased to $2.0 \mathrm{MPa}$ and 2.5 MPa. It is the transition stage that the internal filling structure began to change under a higher gradient with no damage occurred.

When the injection pressure reached $3.0 \mathrm{MPa}$, a rapid increase of the injection flow rate was observed, at the same time, a large amount of reddish-brown muddy water emission observed from the borehole CZK88-1 shows the test section was damaged. The water outlet from the observation borehole was still turbid when injection pressure increased to $3.5 \mathrm{MPa}$. The flow rate had a rapid increase in the middle of this pressure stage, the secondary damage occurred in this section. Then the flow rate dropped rapidly and eventually became stable at the end of the test. There was no change in the head of water table of the observation hole during this process, it may be due to partially damage near the injection borehole, then mud fillings in ISWZ blocked again rapidly to form a new stable state, the water head at the observation hole was not affected.

\section{Results and Discussions}

We performed two tests to estimate the non-Darcian flow properties of ISWZ in two boreholes drilled in zone $\mathrm{C}_{2}$ and $\mathrm{C}_{4}$, respectively. Both the injection boreholes radius $\left(r_{w}\right)$ are $3.75 \mathrm{~cm}$, and the length $(l)$ of the test section is $4 \mathrm{~m}$ in CZK51 and $2 \mathrm{~m}$ in CZK88, respectively. The average thickness of the test section in borehole CZK51 is approximately $0.95 \mathrm{~m}$ and $0.68 \mathrm{~m}$ for the ISWZ $\mathrm{C}_{4}$ in borehole CZK88. According to the above analysis of the HPPT process, two non-Darcian flow models are used to obtain nonDarcian parameters by $\Delta H-Q$ curve fitting. There are two groups values to interpret the test process for each borehole according to the transformation of the internal structure, the first is the stage including the undamaged stage and the transition stage which is used to interpret the flow when the test section is relative integrity, the second shows the seepage characteristics in the damage stage. Due to the flow rate quickly reached a steady-state from the analysis in the previous section, we choose the mean flow rate of each water pressure stage for curve fitting.

\subsection{Non-Darcian Flow Properties of ISWZ}

4.1.1. Borehole CZK51. There are five pressure stages divided into two main parts to obtain the non-Darcian parameters due to the change in test section structure. The first three stages are the undamaged stage, and the last three points are the damaged stage. Note that both stages include the point of the transition stage, the internal structure of the test section in this stage starts to change but not damaged completely as the end of the undamaged stage and the start of the damaged stage.

As is shown in Figure 9(a), the fitting curves obtained by two different non-Darcian flow models both fit well with the observation points. Note that the quadratic term of Forchheimer's law is negative which means the results are meaningless. On the other hand, Izbash's law has good fitting results. The curves obtained by two different nonDarcian flow models in the damage stage is shown in Figure 9(b), the Izbash's law model can fit better than Forchheimer's law model. The corresponding best-fitted nonDarcian flow parameters are shown in Table 2 by Eq.(9) and Eq.(10) for Forchheimer's law and Eq.(20) for Izbash's law, respectively.

4.1.2. Borehole $C Z K 88$. There are nine pressure stages of the borehole CZK88 which is divided into two main parts as well. The undamaged stage includes the pressure stage from $0.3 \mathrm{MPa}$ to $2.5 \mathrm{MPa}$ where there is no damage occurred in these pressure stage. The last three stages are the damage stage which the last point in the transition stage taken into consideration as the start point of the damage.

The fitting results are shown in Figure 10(a), two curves are similar in the undamaged stage. As the obtained nonDarcian parameters shown in Table 3, the seepage feature is similar to the characteristics of borehole CZK51 which the nonlinear term in Forchheimer's law is negative and the nonlinear index is less than 1 in Izbash's law. The increase of head difference is insignificant that it is 


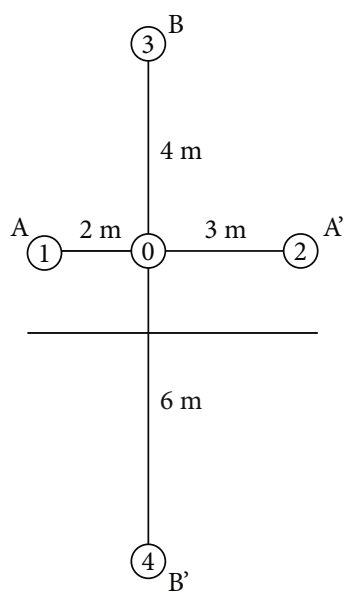

(a)

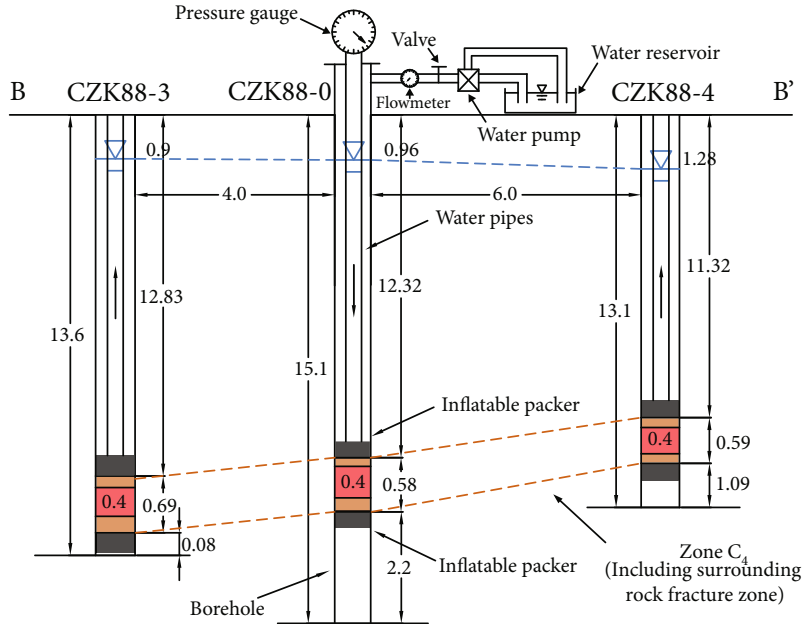

(b)

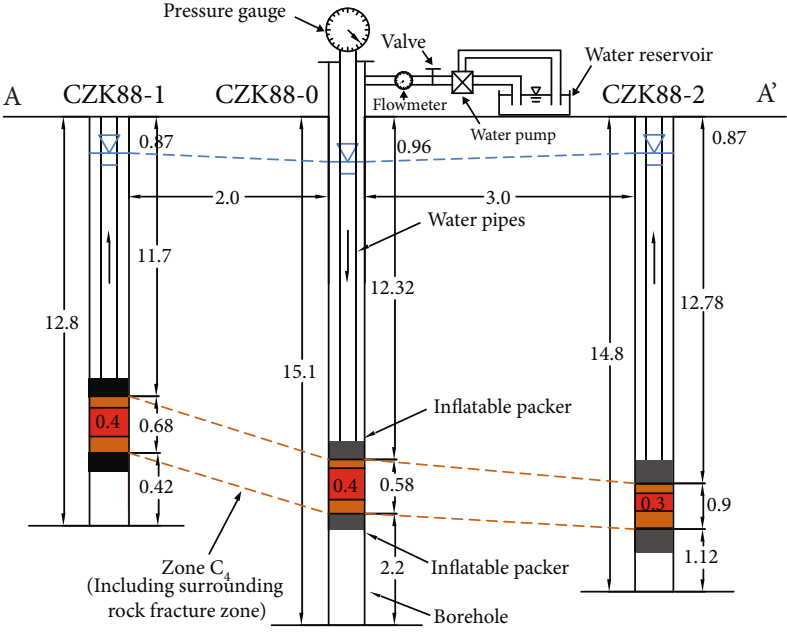

(c)

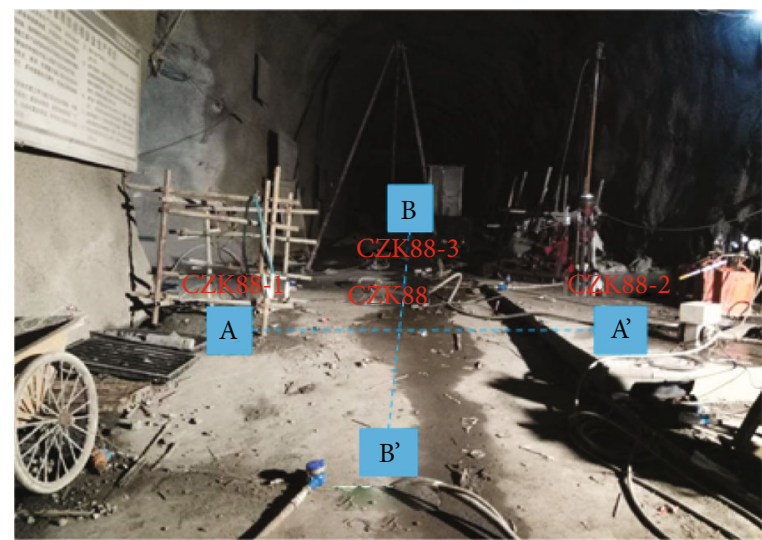

(d)

Figure 7: The distribution and a sectional view of the testing site of borehole CZK88: (a) the spatial distribution of each borehole; (b) the profile of the boreholes in the B-B' section; (c) the profile of the boreholes in the A-A' section; (d) testing field of borehole CZK88 (all dimensions are in units of $\mathrm{m}$ ).

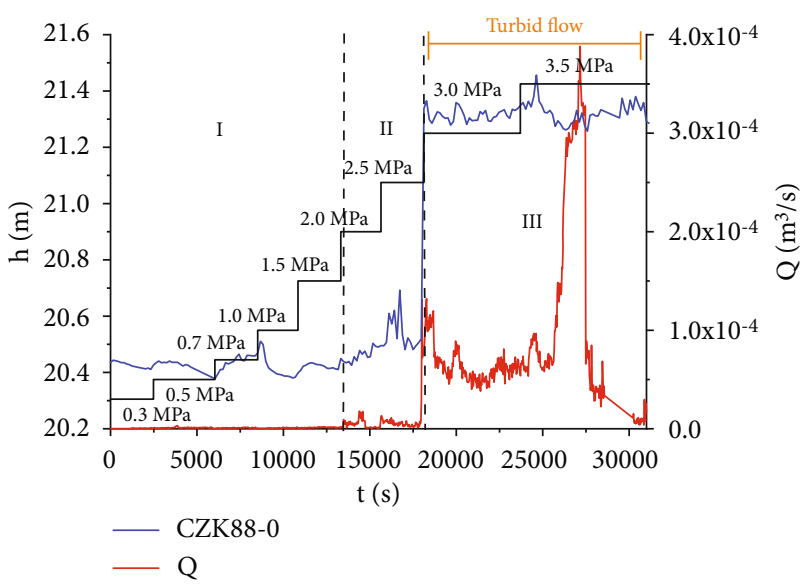

FIGURE 8: Flow rate and head of water table of observation borehole CZK88-1. It can be divided into three stages according to flow variation and observed turbidity, (I) undamaged stage, (II) transition stage and (III) damaged stage. intuitively to see that the curve bends downward. The main reason is the changes in internal structure due to the filling particles gradually washed away leads to the permeability of the test section keeps changing. As can be seen from Figure 10(b), the curve obtained by Forchheimer's law in the damage stage has a similar problem that leads to meaningless results.

It can be seen from the results of the two stages that Izbash's law is more suitable for interpreting the nonDarcian flow of HPPT. Interestingly, the non-Darcian exponent value is between 0 and 1 , which is different from the previous research results of non-Darcian flow in that the value $n$ is between 1 and 2 in a general case [26-30]. Different from these studies, the test process is a more complex process including low permeability medium non-Darcian flow under high gradient and the internal structure changes under high pressure. The partial destruction at the end of the test increased the permeability of ISWZ, causing a rapid increase in flow rate, making the curve deviate from the linear relationship formed in the previous pressure stages. 


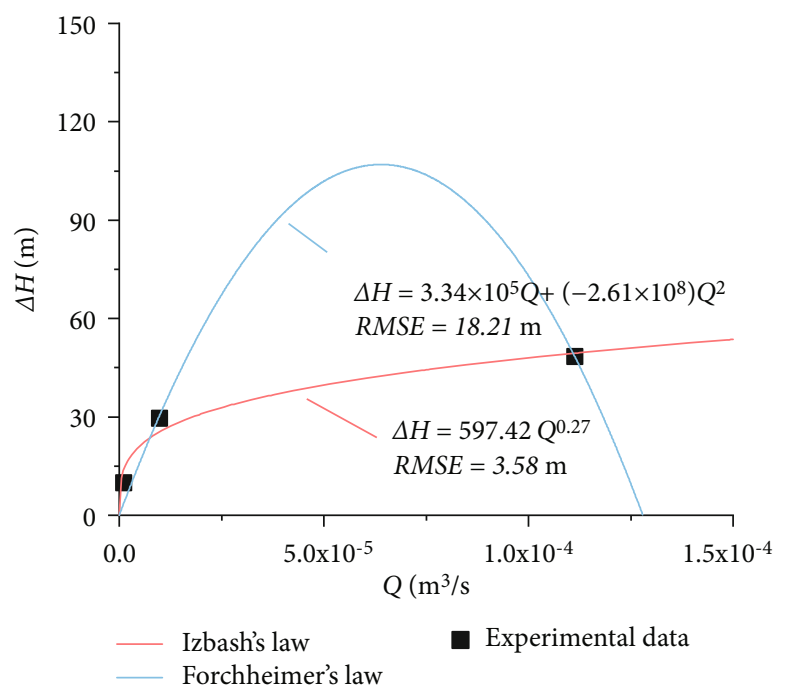

(a)

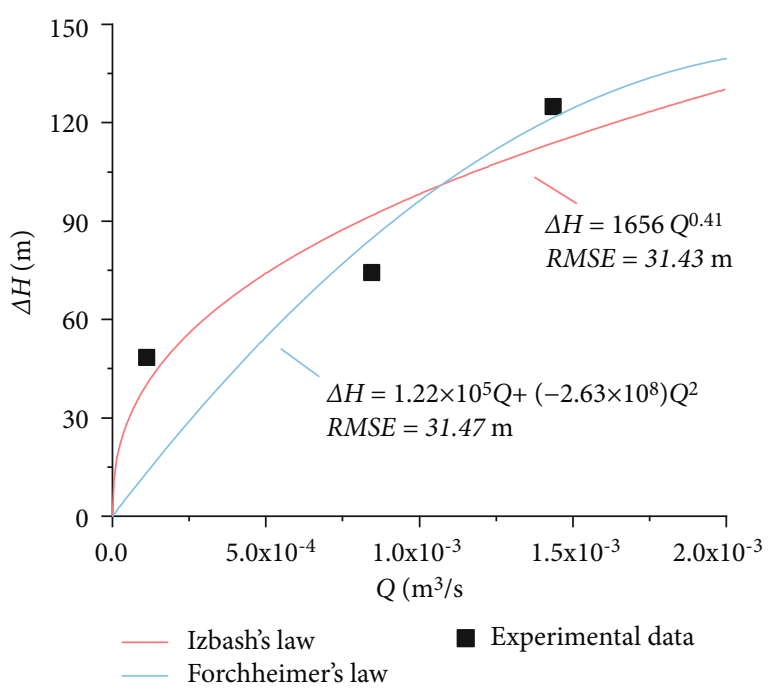

(b)

Figure 9: $\Delta H$-Q curves obtained by different non-Darcian flow models from the HPPT data in borehole CZK51 in (a) undamaged stage and (b) damaged stage.

TABLE 2: Non-Darcian flow parameters estimated from HPPT data in CZK51.

\begin{tabular}{lccccc}
\hline State & \multicolumn{3}{c}{ Forchheimer's law } & \multicolumn{3}{c}{ Izbash's law } \\
& $a / \mathrm{s} \cdot \mathrm{cm}^{-1}$ & $b / \mathrm{s}^{2} \cdot \mathrm{cm}^{-2}$ & $R M S E / \mathrm{m}$ & $K_{c} / \mathrm{cm}^{-1} \mathrm{~s}^{-1}$ & $R M S E / \mathrm{m}$ \\
\hline Undamaged stage & $4.27 \times 10^{7}$ & $-4.44 \times 10^{10}$ & 18.21 & $1.05 \times 10^{-7}$ & 0.27 \\
Damaged stage & $1.56 \times 10^{7}$ & $-4.48 \times 10^{9}$ & 21.22 & $5.51 \times 10^{-6}$ & 0.41 \\
\hline
\end{tabular}

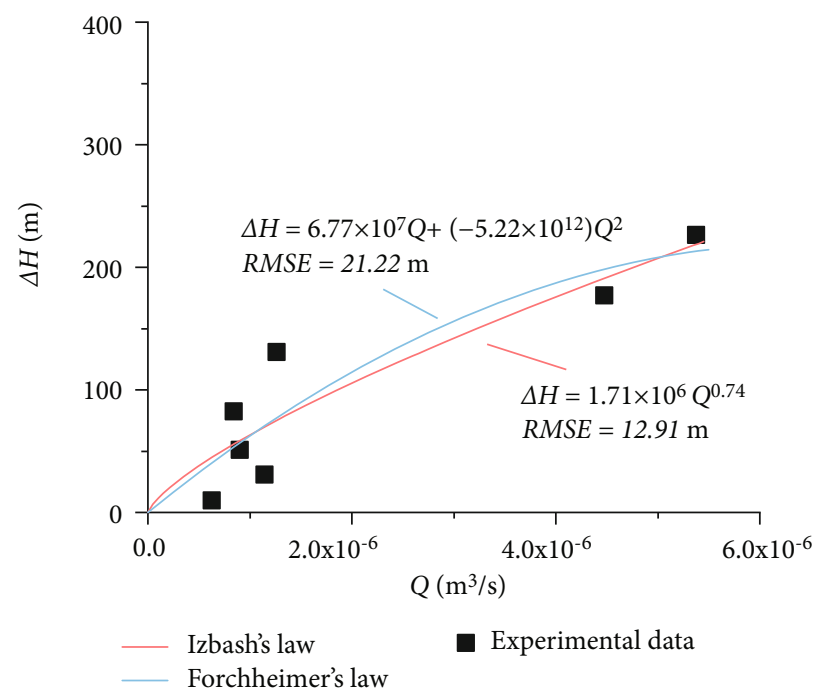

(a)

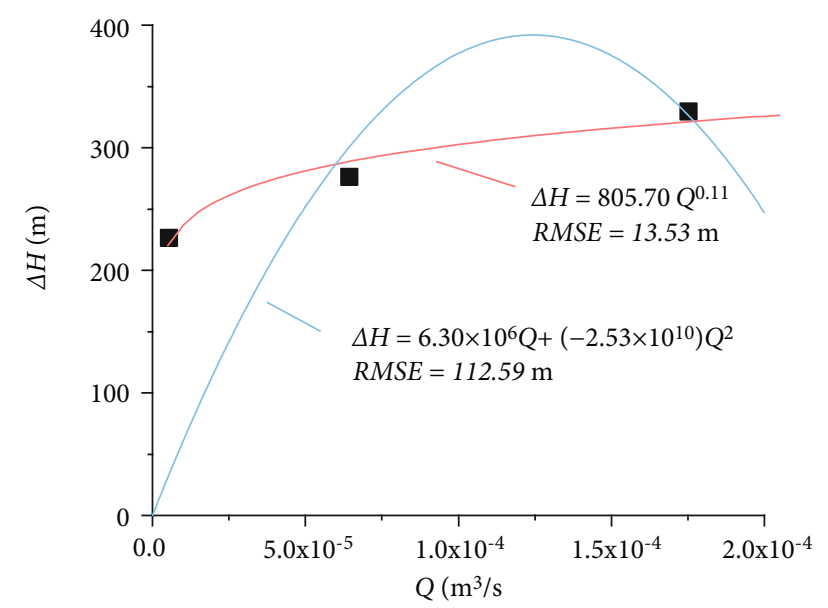

— Izbash's law Forchheimer's law

(b)

Figure 10: $\Delta H$-Q curves obtained by different non-Darcian flow models from the HPPT data in borehole CZK88 in (a) undamaged stage and (b) damaged stage.

TABLE 3: Non-Darcian flow parameters estimated from HPPT data in CZK88.

\begin{tabular}{|c|c|c|c|c|c|c|}
\hline \multirow{2}{*}{ State } & \multicolumn{3}{|c|}{ Forchheimer's law } & \multicolumn{3}{|c|}{ Izbash's law } \\
\hline & $a / s \cdot \mathrm{cm}^{-1}$ & $\mathrm{~b} / \mathrm{s}^{2} \cdot \mathrm{cm}^{-2}$ & $R M S E / \mathrm{m}$ & $K_{c} / \mathrm{cm} \cdot \mathrm{s}^{-1}$ & $n$ & $R M S E / \mathrm{m}$ \\
\hline Undamaged stage & $7.27 \times 10^{9}$ & $-1.75 \times 10^{15}$ & 31.47 & $3.85 \times 10^{-7}$ & 0.74 & 31.43 \\
\hline Damaged stage & $1.56 \times 10^{8}$ & $-8.48 \times 10^{12}$ & 112.59 & $5.36 \times 10^{-23}$ & 0.11 & 13.53 \\
\hline
\end{tabular}



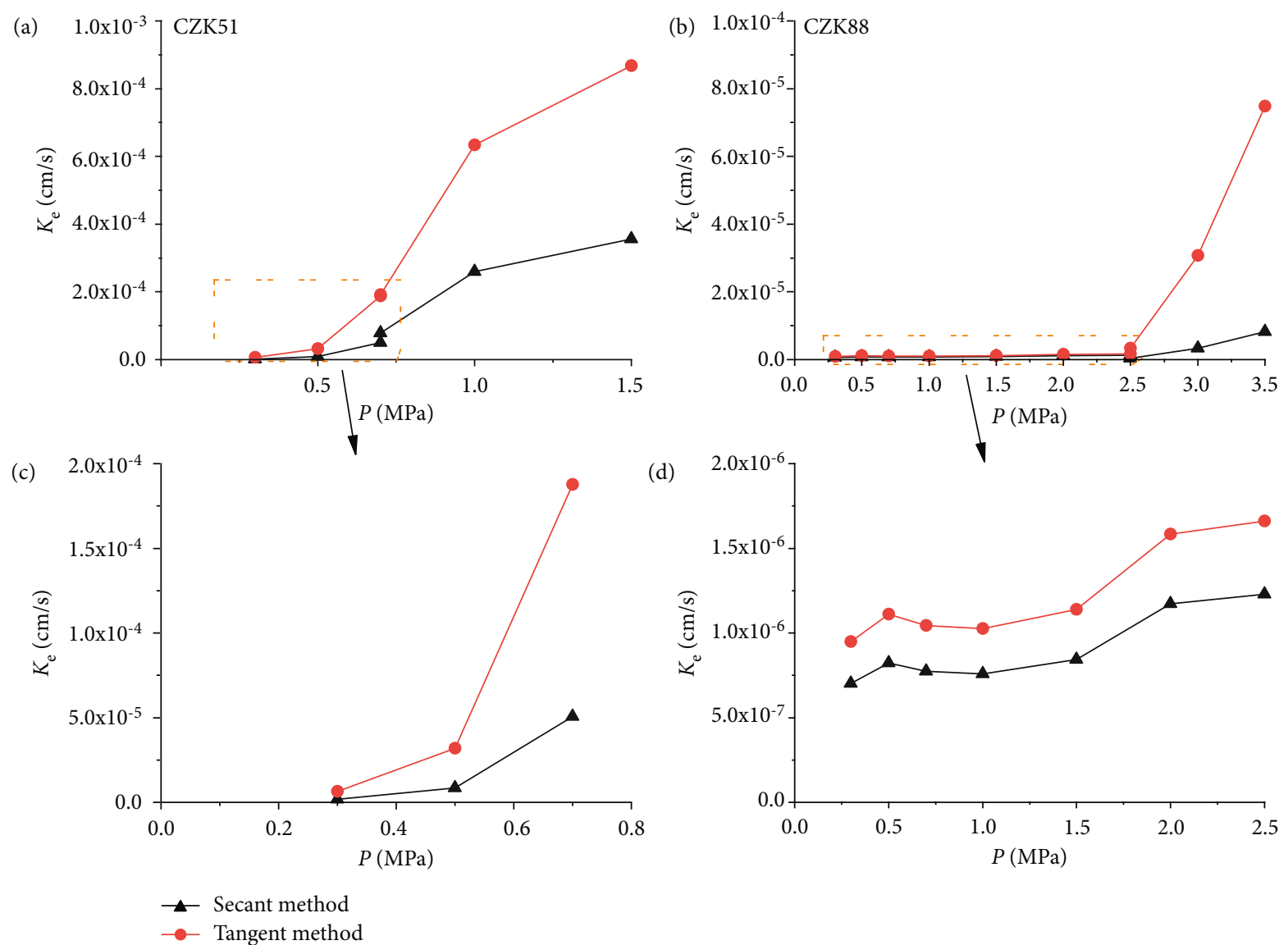

(d)

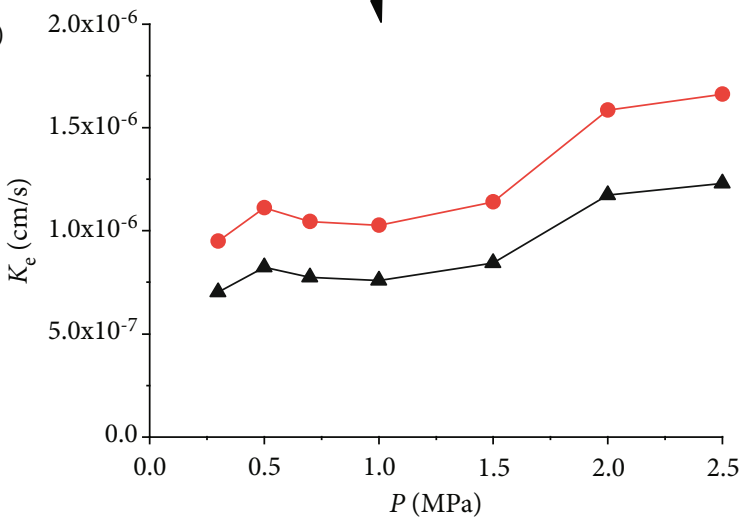

FIGURE 11: The variation of equivalent permeability coefficient in different pressure stage in the borehole (a)CZK51 and (b)CZK88, with the detailed results of the undamaged stage in (c)CZK51 and (d)CZK88.

4.2. The Variation of Equivalent Permeability Coefficient. Due to the Izbash's law fits better for the HPPT, the two kinds of equivalent permeability coefficient can be obtained from the fitting results by this model, it can be written as

$$
\begin{aligned}
K_{e s i} & =\frac{K_{c}{ }^{n}}{v^{n-1}}=\frac{K_{c}{ }^{n}}{(Q / 2 \pi r M)^{n-1}} \\
K_{e t i} & =\frac{K_{c}{ }^{n}}{n v^{n-1}}=\frac{K_{c}{ }^{n}}{n(Q / 2 \pi r M)^{n-1}}
\end{aligned}
$$

As is shown in Figures 11(a), 11(c) and Table 4, the equivalent permeability of borehole CZK51 obtained by the tangent method is larger than the secant method. As the flow rate increase, the difference between the two values continues to increase. These values show the test section has better permeability and there is a growing process that the internal structure of the test section is continuous change with the filling washed away. Especially in the damaged stage, the value increases rapidly, at the same time, the difference of value is larger between the two methods due to the nonlinear exponent $n$ is smaller which the value obtained by the tangent method has a larger multiple than the value obtained by secant method. This means the real value of equivalent permeability underestimated in the last injection pressure stage. The increase of permeability coefficient in
TABLE 4: The obtained equivalent permeability coefficient under different injection pressure by two methods in borehole CZK51.

\begin{tabular}{lccc}
\hline $\begin{array}{l}\text { Test section } \\
\text { status }\end{array}$ & $\begin{array}{c}\text { Injection } \\
\text { pressure (MPa) }\end{array}$ & \multicolumn{2}{c}{$\begin{array}{c}\text { Equivalent permeability } \\
\text { coefficient }(\mathrm{cm} / \mathrm{s})\end{array}$} \\
& 0.3 & $1.73 \times 10^{-6}$ & $6.40 \times 10^{-6}$ \\
Secant method & Tangent method \\
Undamaged & 0.5 & $8.61 \times 10^{-6}$ & $3.19 \times 10^{-5}$ \\
& 0.7 & $5.06 \times 10^{-5}$ & $1.88 \times 10^{-4}$ \\
\hline \multirow{3}{*}{ Damaged } & 0.7 & $7.85 \times 10^{-5}$ & $1.91 \times 10^{-4}$ \\
& 1.0 & $2.60 \times 10^{-4}$ & $6.33 \times 10^{-4}$ \\
& 1.5 & $3.56 \times 10^{-4}$ & $8.68 \times 10^{-4}$ \\
\hline
\end{tabular}

the transition stage indicates damage begins to occur under the injection pressure of 0.7 MPa. Meanwhile, two values in the transition stage obtained by different fitting results in different conditions. There is little difference between these two values by fitting error.

As is shown in Figure 11(b) and Table 5, the equivalent permeability of borehole CZK88 has segmented features. The value obtained by the tangent method is larger which is shown in Figure 11(d). The main difference is in the damaged stage that the tangent method value is about one order of magnitude larger than the secant method. The reason for the obvious difference is the same as the results in CZK51 
TABLE 5: The obtained equivalent permeability coefficient under different injection pressure by two methods in borehole CZK88.

\begin{tabular}{lccc}
\hline $\begin{array}{l}\text { Test section } \\
\text { status }\end{array}$ & $\begin{array}{c}\text { Injection } \\
\text { pressure (MPa) }\end{array}$ & \multicolumn{2}{c}{$\begin{array}{c}\text { Equivalent permeability } \\
\text { coefficient }(\mathrm{cm} / \mathrm{s})\end{array}$} \\
& 0.3 & $7.03 \times 10^{-7}$ & $9.50 \times 10^{-7}$ \\
& 0.5 & $8.22 \times 10^{-7}$ & $1.11 \times 10^{-6}$ \\
& 0.7 & $7.73 \times 10^{-7}$ & $1.04 \times 10^{-6}$ \\
Sndamaged & 1.0 & $7.59 \times 10^{-7}$ & $1.03 \times 10^{-6}$ \\
& 1.5 & $8.43 \times 10^{-7}$ & $1.14 \times 10^{-6}$ \\
& 2.0 & $1.17 \times 10^{-6}$ & $1.58 \times 10^{-6}$ \\
& 2.5 & $1.23 \times 10^{-6}$ & $1.66 \times 10^{-6}$ \\
\hline \multirow{3}{*}{ Damaged } & 2.5 & $3.70 \times 10^{-7}$ & $3.36 \times 10^{-6}$ \\
& 3.0 & $3.37 \times 10^{-6}$ & $3.07 \times 10^{-5}$ \\
& 3.5 & $8.22 \times 10^{-6}$ & $7.48 \times 10^{-5}$ \\
\hline
\end{tabular}

which the relatively small value of $n$ causes such a big difference. The equivalent permeability coefficients of the damaged stage are underestimated. It means the permeability of the test section after the damage is better than expected in the actual case, which should pay attention to this difference.

\section{Summary and Conclusions}

There are few studies on the permeability of the ISWZs under the non-Darcian flow condition which is vital to the stability of rock mass. In this study, two non-Darcian flow models such as Forchheimer's law and Izbash's law were improved to describe the relationship of $\Delta H$ and $Q$ during the high-pressure packer test process. Then, a detailed analysis of the complete pressure process of HPPT in ISWZs was performed. These two models have the advantage of a simple, easy operation and high accuracy, it has good value for promotion and application. However, these methods have high demanding testing conditions that water flow needs to reach a stable value at each pressure stage.

The ISWZ has a complex internal structure that the flow is observed highly nonlinear during the whole HPPT process. It can be found that by fitting the stable value of $\Delta H$ and $Q$ at each pressure stage, Izbash's law has a better fit than Forchheimer's law. Meanwhile, the equivalent permeability coefficient of the damage stage in the range of $1 \times 10^{-6} \mathrm{~cm} / \mathrm{s}$ and $1 \times 10^{-7} \mathrm{~cm} / \mathrm{s}$ is one or two orders of magnitude higher than that of the undamaged stage in the range of $1 \times 10^{-4} \mathrm{~cm} / \mathrm{s}$ and $1 \times 10^{-5} \mathrm{~cm} / \mathrm{s}$ by using the fitting parameters. The difference between the equivalent permeability coefficients obtained by the two methods will be more visible with higher gradient $(i)$ or velocity $(v)$. It is necessary to pay attention to this point in the study of non-Darcian flow.

\section{Nomenclature}

$\begin{array}{ll}H: & \text { Head of water table } \\ r: & \text { Radial coordinate } \\ q: & \text { Specific discharge }\end{array}$ $v: \quad$ Fluid velocity

Q: Volumetric flow rate

M: Thickness of the aquifer

$i$ : Hydraulic Gradient

a: Coefficient describing viscous energy losses

$b$ : Coefficient describing inertial energy losses

$\mu$ : $\quad$ Fluid dynamic viscosity

$\rho$ : $\quad$ Fluid density

$k$ : Permeability

$g$ : Gravitational acceleration

$K$ : Permeability coefficient for laminar flow

$\beta$ : $\quad$ Nonlinear flow coefficient

$h_{w}$ : Head of water table of the test well with the radius $r_{w}$

$r_{w}$ : Well radius

$h_{1}$ : Head of water table of the observation well

$r_{1}$ : Radial between injection borehole and observation borehole

P: $\quad$ Pressure

$\Delta H$ : Head difference

A: $\quad$ Fitting parameter

$B: \quad$ Fitting parameter

$n$ : Nonlinear flow exponent

$K_{c}$ : Nonlinear flow hydraulic permeability for Izbash's law

C: Constant

$C_{1}:$ Fitting parameter

$K_{e}: \quad$ Equivalent permeability coefficient

\section{Data Availability}

The test data used to support the findings of this study are available from the corresponding author upon request.

\section{Conflicts of Interest}

The authors declare that they have no known competing financial interests or personal relationships that could have appeared to influence the work reported in this paper.

\section{Acknowledgments}

This work was supported by the Major Program of the National Natural Science Foundation of China (Grant No. 91747204).

\section{References}

[1] D.-P. Xu, X.-T. Feng, and Y.-J. Cui, "A simple shear strength model for interlayer shear weakness zone," Engineering Geology, vol. 147-148, pp. 114-123, 2012.

[2] D.-P. Xu, X.-T. Feng, and Y.-J. Cui, “An experimental study on the shear strength behaviour of an interlayered shear weakness zone," Bulletin of Engineering Geology and the Environment, vol. 72, no. 3-4, pp. 327-338, 2013.

[3] D.-P. Xu, X.-T. Feng, Y.-J. Cui, and Q. Jiang, "Use of the equivalent continuum approach to model the behavior of a rock mass containing an interlayer shear weakness zone in an underground cavern excavation," Tunnelling and Underground Space Technology, vol. 47, pp. 35-51, 2015.

[4] M. Chen, Z. Zhou, L. Zhao, M. Lin, Q. Guo, and M. Li, "Study of the Scale Effect on Permeability in the Interlayer Shear 
Weakness Zone Using Sequential Indicator Simulation and Sequential Gaussian Simulation," Water, vol. 10, no. 6, p. 779, 2018.

[5] Z. F. Zhou, M. Lin, Q. N. Guo, and M. Chen, "Scale effect and value criterion of the permeability of the interlayer staggered zones in the basalt of Jinsha River basin, China," Hydrogeology Journal, vol. 26, no. 5, pp. 1731-1748, 2018.

[6] F. H. Cornet and R. H. Morin, "Evaluation of hydromechanical coupling in a granite rock mass from a high- volume, highpressure injection experiment: Le Mayet de Montagne, France," International Journal of Rock Mechanics and Mining Sciences, vol. 34, no. 3-4, pp. 207.e1-207.e14, 1997.

[7] F. Cappa, Y. Guglielmi, J. Rutqvist, C. F. Tsang, and A. Thoraval, "Hydromechanical modelling of pulse tests that measure fluid pressure and fracture normal displacement at the Coaraze Laboratory site, France," International Journal of Rock Mechanics and Mining Sciences, vol. 43, no. 7, pp. 1062-1082, 2006.

[8] B. Derode, F. Cappa, Y. Guglielmi, and J. Rutqvist, "Coupled seismo-hydromechanical monitoring of inelastic effects on injection- induced fracture permeability," International Journal of Rock Mechanics and Mining Sciences, vol. 61, pp. 266274, 2013.

[9] Z. Huang, Z. Q. Jiang, S. Y. Zhu, Z. Qian, and D. Cao, “Characterizing the hydraulic conductivity of rock formations between deep coal and aquifers using injection tests," International Journal of Rock Mechanics and Mining Sciences, vol. 71, pp. 12-18, 2014.

[10] C. Braester and R. Thunvik, "Determination of formation permeability by double-packer tests," Journal of Hydrology, vol. 72, no. 3-4, pp. 375-389, 1984.

[11] K. S. Novakowski and P. A. Lapcevic, "Field measurement of radial solute transport in fractured rock," Water Resources Research, vol. 30, no. 1, pp. 37-44, 1994.

[12] J. Rutqvist, J. Noorishad, C.-F. Tsang, and O. Stephansson, "Determination of fracture storativity in hard rocks using high-pressure injection testing," Water Resources Research, vol. 34, no. 10, pp. 2551-2560, 1998.

[13] P. M. Quinn, J. A. Cherry, and B. L. Parker, "Quantification of non-Darcian flow observed during packer testing in fractured sedimentary rock," Water Resources Research, vol. 47, no. 9, 2011.

[14] P. M. Quinn, B. L. Parker, and J. A. Cherry, "Validation of non-Darcian flow effects in slug tests conducted in fractured rock boreholes," Journal of Hydrology, vol. 486, pp. 505-518, 2013.

[15] D. Elsworth and T. W. Doe, "Application of non-linear flow laws in determining rock fissure geometry from single borehole pumping tests," International Journal of Rock Mechanics and Mining Sciences \& Geomechanics Abstracts, vol. 23, no. 3, pp. 245-254, 1986.

[16] Z. Zhou, Z. Wang, S. Li, Q. Shen, M. Chen, and H. Zheng, "Determination of nonlinear seepage slope for dislocation interface by in situ tests," Bulletin of Engineering Geology and the Environment, vol. 80, no. 3, pp. 2765-2775, 2021.

[17] H. Yamada, F. Nakamura, Y. Watanabe, M. Murakami, and T. Nogami, "Measuring hydraulic permeability in a streambed using the packer test," Hydrological Processes, vol. 19, no. 13, pp. 2507-2524, 2005.

[18] Y. F. Chen, M. M. Liu, S. H. Hu, and C. B. Zhou, "Non-Darcy's law-based analytical models for data interpretation of high- pressure packer tests in fractured rocks," Engineering Geology, vol. 199, pp. 91-106, 2015.

[19] Y.-F. Chen, Z. Liao, J.-Q. Zhou et al., "Non-Darcian flow effect on discharge into a tunnel in karst aquifers," International Journal of Rock Mechanics and Mining Sciences, vol. 130, article 104319, 2020.

[20] M. J. Hvorslev, Time lag and soil permeability in ground-water observations, Waterways Experiment Station, Corps of Engineers, US Army, 1951.

[21] M. G. Sidiropoulou, K. N. Moutsopoulos, and V. A. Tsihrintzis, "Determination of Forchheimer equation coefficientsa andb," Hydrological Processes, vol. 21, no. 4, pp. 534-554, 2007.

[22] D. Ruth and H. Ma, "On the derivation of the Forchheimer equation by means of the averaging theorem," Transport in Porous Media, vol. 7, no. 3, pp. 255-264, 1992.

[23] C. Cherubini, C. I. Giasi, and N. Pastore, "Bench scale laboratory tests to analyze non-linear flow in fractured media," Hydrology and Earth System Sciences, vol. 16, no. 8, pp. 2511-2522, 2012.

[24] K. N. Moutsopoulos, I. N. E. Papaspyros, and V. A. Tsihrintzis, "Experimental investigation of inertial flow processes in porous media," Journal of Hydrology, vol. 374, no. 3-4, pp. 242-254, 2009.

[25] M. Zoorabadi, S. Saydam, W. Timms, and B. Hebblewhite, "Non-linear flow behaviour of rough fractures having standard JRC profiles," International Journal of Rock Mechanics and Mining Sciences, vol. 76, pp. 192-199, 2015.

[26] Y.-F. Chen, S.-H. Hu, R. Hu, and C.-B. Zhou, "Estimating hydraulic conductivity of fractured rocks from high-pressure packer tests with an Izbash's law-based empirical model," Water Resources Research, vol. 51, no. 4, pp. 2096-2118, 2015.

[27] Q. R. Wang, H. B. Zhan, and Y. X. Wang, "Non-Darcian effect on slug test in a leaky confined aquifer," Journal of Hydrology, vol. 527, pp. 747-753, 2015.

[28] L. Xiao, M. Ye, Y. Xu, and F. Gan, "A Simplified Solution Using Izbash's Equation for Non-Darcian Flow in a Constant Rate Pumping Test," Groundwater, vol. 57, no. 6, pp. 962968, 2019.

[29] K. Tu, Q. Wu, J. Simunek et al., “An approximate analytical solution for non-Darcian flow in a confined aquifer with a single well circulation groundwater heat pump system," Advances in Water Resources, vol. 145, article 103740, 2020.

[30] Y. B. Li, Z. F. Zhou, C. Zhuang, Y. Huang, and J. Wang, "NonDarcian effect on a variable-rate pumping test in a confined aquifer," Hydrogeology Journal, vol. 28, no. 8, pp. 2853-2863, 2020. 